$\mathbf{R}_{\text {ESEARCH }} \mathbf{P}_{\text {APER }} \longrightarrow$ FOOD SCIENCE

e ISSN-2230-9403 — Visit us : www.researchjournal.co.in Volume 8 | Issue 1 | April, 2017 | 59-63 DOI : 10.15740/HAS/FSRJ/8.1/59-63

\title{
Studies on development of low calorie pineapple RTS beverage by using artificial sweeteners
}

\author{
B. Mansoor, A.R. Sawate, B.M. Patil and R.B. Kshirsagar
}

In present investigation efforts have been made to prepare low calorie pineapple RTS beverage by using different combination of artificial sweeteners (aspartame and sucralose) and sugar (sucrose). Further the effect of artificial sweeteners on chemical charecterstics and sensory acceptability of low calorie pineapple RTS beverage was evaluated. The study revealed that good quality and organoleptically acceptable low calorie pineapple RTS beverage can be prepared by using $50 \%$ sucrose $+50 \%$ sucralose.

Key Words : Pineapple, Aspartame, Sucralose, RTS beverage

How to cite this article : Mansoor, B., Sawate, A.R., Patil, B.M. and Kshirsagar, R.B. (2017). Studies on development of low calorie pineapple RTS beverage by using artificial sweeteners. Food Sci. Res. J., 8(1): 59-63, DOI : 10.15740/HAS/FSRJ/8.1/59-63. 